\title{
Evaluation of Placental Perfusion Based on Intravoxel Incoherent Motion Diffusion Weighted Imaging (IVIM-DWI) and Its Predictive Value for Late-Onset Fetal Growth Restriction
}

\section{Einsatz von Intravoxel-Incoherent-Motion-diffusionsgewichteter Bildgebung (IVIM-DWI) zur Bewertung der Plazentadurchblutung und die prognostische Wertigkeit für eine späte fetale Wachstums- restriktion}

\section{(ㄷ) (1) (오 $\Theta$}

Authors

Hui Shi ${ }^{1}$, Xianyue Quan ${ }^{1}$, Wen Liang ${ }^{1}$, Xinming Li $^{1}$, Bin Ai ${ }^{2}$, Hongsheng Liu ${ }^{2}$

Affiliations

1 Department of Medical Image Center, Zhujiang Hospital, Southern Medical University, Guangzhou, China

2 Department of Medical Image, Guangzhou Women and Children's Medical Center, Guangzhou, China

Key words

late-onset FGR, IVIM-DWI, perfusion fraction, IUGR

Schlüsselwörter

späte fetale Wachstumsrestriktion, IVIM-DWI, Perfusionsanteil, IUGR

received 16.5 .2018

revised 22.8.2018

accepted 26.8.2018

\section{Bibliography}

DOI https://doi.org/10.1055/a-0717-5275

Published online 12.12.2018 | Geburtsh Frauenheilk 2019; 79: 396-401 @ Georg Thieme Verlag KG Stuttgart .

New York | ISSN 0016-5751

Correspondence

Dr. Hongsheng Liu

Department of Radiology, Guangzhou Women and Children's Medical Center

No. 318 Renmin Rd., Guangzhou 510120, Guangdong,

People's Republic of China

liuhs72@163.com

\section{ABSTRACT}

Objective The aim of this study was to investigate placental blood perfusion in middle and late pregnancy and explore its predictive value for fetal growth restriction (FGR).

Methods All pregnant women included in the study were examined using placental intravoxel incoherent motion diffusion-weighted imaging (IVIM-DWI). Three IVIM parameters $\left(D, f, D^{*}\right)$ were obtained for each pregnant woman and analyzed using Image J software. Perfusion fraction $\mathrm{f}$ is a radiological marker of placental perfusion. The pulsatility index (PI) of the uterine artery is used to indirectly evaluate placental function.

Results $\mathrm{f}$-values were significantly lower in the late-onset FGR group compared to the normal late pregnancy group (19.07 vs. $27.78 \%$ ). In addition, uterine artery PI values were markedly increased in the late-onset FGR group compared to the normal late pregnancy group (1.96 vs. 1.03), and neonatal weight was significantly lower in the late-onset FGR group $(2.75$ vs. $3.18 \mathrm{~kg})$. There was a significant positive correlation between $\mathrm{f}$-value, uterine artery $\mathrm{PI}$ and neonatal weight $(r=0.968, p<0.01 ; r=0.959, p<0.01)$. There was a significant negative correlation between $\mathrm{f}$-value and age of gestation $(r=-0.534, p<0.01)$.

Conclusion Perfusion fraction $\mathrm{f}$ was strongly correlated with uterine artery blood flow resistance as measured by color Doppler and had a certain predictive value for late-onset FGR.

\section{ZUSAMMENFASSUNG}

Zlel Ziel dieser Studie war es, die Plazentadurchblutung während der mittleren und späten Schwangerschaft zu untersuchen und den prognostischen Wert für die fetale Wachstumsrestriktion zu erkunden.

Methode Alle in die Studie aufgenommenen schwangeren Frauen wurden mittels Intravoxel Incoherent Motion diffusionsgewichteter Bildgebung (IVIM-DWI) untersucht. Es wur- 
den jeweils 3 IVIM Parameter ( $D, f, D^{*}$ ) für jede der schwangeren Frauen gewonnen, die Parameter wurden mithilfe der Image J Software analysiert. Der Perfusionsanteilswert f stellt ein radiologischer Marker für die Durchblutung der Plazenta dar. Der Pulsatilitätsindex (PI) der Nabelschnur kann zur indirekten Bewertung der Plazentafunktion benutzt werden.

Ergebnisse Die f-Werte der Gruppe mit spät einsetzender fetaler Wachstumsrestriktion waren deutlich niedriger verglichen mit der Gruppe von Frauen mit normaler Spätschwangerschaft (19,07 vs. 27,78\%). Hinzu kam noch, dass die PIWerte in der Gruppe mit spät einsetzender fetaler Wachstumsrestriktion deutlich erhöht waren, verglichen mit der Gruppe von Frauen mit normaler Spätschwangerschaft (1,96 vs. 1,03); auch das Geburtsgewicht war signifikant niedriger in der Gruppe mit spät einsetzender fetaler Wachstumsrestriktion (2,75 vs. $3,18 \mathrm{~kg}$ ). Es gab eine signifikante positive Korrelation zwischen dem f-Wert, dem PI-Wert der Umbilikalgefäße und dem Geburtsgewicht $(r=0,968, \quad p<0,01$; $r=0,959, p<0,01)$. Ferner bestand eine statistisch signifikante negative Korrelation zwischen dem f-Wert und dem Gestationsalter $(r=-0,534, p<0,01)$.

Schlussfolgerung Der Perfusionsanteilswert $f$ korrelierte stark mit dem mit Farbdoppler gemessenen Strömungswiderstand in der Nabelschnur und hatte einen gewissen prognostischen Wert für die spät einsetzende fetale Wachstumsrestriktion.

\section{Introduction}

Fetal growth restriction (FGR) is considered late onset when it occurs after 32 weeks of gestation. Late-onset FGR is mainly asymmetrical because of its close relationship with utero-placental insufficiency and insufficient microcirculation of the placental villi $[1,2]$. FGR is associated with a higher rate of stillbirths, neonatal mortality, and perinatal and neonatal morbidity. Timely prenatal and intrapartum treatment can improve the prognosis of FGR, while successful treatment of FGR during pregnancy depends on early diagnosis.

An accurate quantitative evaluation of placental perfusion can allow clinicians to plan the delivery and improve the management of the neonate. Color Doppler is currently used during middle and late pregnancy to measure the resistance index of uterine artery blood flow, which serves as an indirect measurement of placental perfusion. However, because of problems such as angle dependence and aliasing and a low sensitivity to low velocity blood flow, color Doppler can only provide indirect parameters of blood flow resistance. In addition, the technique also depends on the experience of the operator, and repeatability is poor. Polyhydramnios, maternal obesity and posterior wall placenta significantly reduce the accuracy of this technique.

In 1986, Le Bihan et al. [3] developed a method which used MR imaging to generate images of intravoxel incoherent motions (IVIM). They separated tissue diffusion (slow diffusion) from capillary perfusion (rapid diffusion) by using a series of diffusion-sensitive factor-b values. Because IVIM has the advantage that it is a non-contrast-enhanced imaging technique, it has become a focus of research over the past decade. Existing studies have confirmed that IVIM can provide important diagnostic information on disorders of placental function such as preeclampsia and intrauterine growth retardation [4-7].

This study summarizes our experience with the use of this technique for the assessment of placental blood perfusion in middle and late pregnancy and preliminarily explores its predictive value for FGR. A prospective study with a larger study population is planned.

\section{Methods}

\section{Study population}

This study was approved by the Ethics Committee of Guangzhou Women and Children's Medical Center. Written informed consent was obtained from all subjects.

A total of 60 women (mean age $=29 \pm 3$ years, range: 18 44 years) with singleton pregnancies whose initial ultrasound examination was suspicious for a disorder or fetal malformation underwent MRI examination in the Guangzhou Women and Children Medical Center between June 2014 and February 2015. The 60 subjects were divided into 3 groups according to age of gestation (GA): group $A(G A=24-28$ weeks), group $B(G A=28-$ 32 weeks), group $C(G A=32-38$ weeks, normal late pregnancy group).

Exclusion criteria were:

1. placental abnormality (e.g., abnormal placental implantation, placenta previa, vasa previa, placental infarction, placental hematoma, placental abruption, or infectious placental lesions);

2. twin or multiple pregnancy;

3. maternal metabolic disease which could have a potential effect on placental function, such as hyperthyroidism;

4. general contraindications to MRI examination, such as claustrophobia;

5. incomplete IVIM diffusion-weighted images (IVIM-DWI).

At 32 weeks of pregnancy, 13 pregnancies were diagnosed as FGR during outpatient examination or inpatient diagnosis. Menstrual cycles were verified. The diagnostic criteria used for FGR followed those of the Obstetrics and Gynecology textbook (7th edition): body weight of the term fetus ( $\geq 37$ weeks) less than $2500 \mathrm{~g}$; or fetal weight below the tenth percentile of the standard curve; or fetal weight below two standard deviations of the average weight of a fetus of the same GA. The fetal weight curve used in our study referred to normal fetal growth values for Guangzhou, China. 


\section{Examination method}

A double gradient MRI scanner (Philips Achieva 1.5 T, Japan) was used to perform the examinations. None of the pregnant women were given a sedative or a contrast agent. To reduce maternal intestinal motion and fetal movement artifacts, scanning was either done in the morning or at a time when fetal movement was reduced. All of the pregnant women were fasting when they had the scan. The fetuses were first examined using conventional scans to identify suspected disorders. This was followed by IVIM-DWI, and peak SAR was recorded.

IVIM-DWI was carried out by respiratory-triggered single-shot echo-planar imaging (SSEPI) using the following parameters: TR 5800 ms; TE $105 \mathrm{~ms}$; flip angle $90^{\circ}$; slice thickness $7 \mathrm{~mm}$; slice gap $0.5 \mathrm{~mm}$; number of layers 20-24; field of view (FOV) $24 \times 24 \mathrm{~cm}$; matrix $192 \times 192$; number of excitations $(\mathrm{NEX})=2$; $\mathrm{b}=0,10,30,50,70,100,150,200,500,800$ and $1000 \mathrm{~s} / \mathrm{mm}^{2}$. The scan time was 7 minutes and 33 seconds. Scans focused on the central part of the placenta, i.e., the scan was centered on the attachment of the umbilical cord and included the whole placenta.

\section{Image processing and parameter measurement}

The manufacturer-supplied software (PRIDE DWI Tool, Version 1.5, Philips Healthcare, Japan) was used for image processing. A bi-exponential curve model to fit the bi-exponential IVIM (biexpIVIM) was selected to generate perfusion-related parameter ( $f$, $\left.D^{*}\right)$ and simple diffusion parameter (D) diagrams. All three parameters $\left(D, f, D^{*}\right)$ were measured in each pregnant woman using Image J software, with measurements carried out by two deputy chief physicians with more than 5 years' experience of placental DWI.

\section{Statistical analysis}

IBM SPSS Statistics 20 software was used for statistical analysis. All data were expressed as means \pm standard deviation (SD). Intraclass correlation coefficient (ICC) was used to evaluate measurement consistency between observers. The f-values of the normal late pregnancy group and of the late-onset FGR group were compared using a normal distribution test and two independent samples t-test. Linear correlation analysis was used to analyze the relationship between placental perfusion parameters and GA in normal middle and late pregnancy and the relationship between $\mathrm{f}$ values of the late-onset FGR group and uterine artery PI values and neonatal weight. $\mathrm{P}<0.05$ was considered statistically significant.
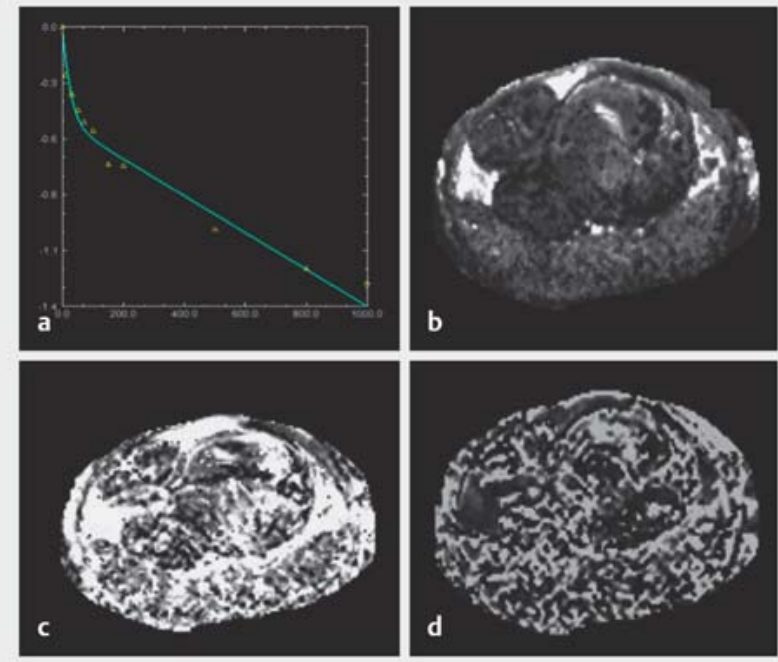

- Fig. 1 IVIM-DWI double fitting curve, perfusion-related parameter diagrams and a simple diffusion model diagram. The patient was in her 34th week of pregnancy and aged 32 years. a The DWI signal attenuates as the b-value increases. The solid line represents a biexponential IVIM model. The signal attenuation curve of the placenta shows a clear "hockey-stick" shape, which indicates that signal attenuation conforms to the typical rule of bi-exponential decay. The turning point occurred when the b-value was $100 \mathrm{~s} /$ $\mathrm{mm}^{2}$. b D value curve. This reflects the diffusion of pure water molecules, the corresponding $\mathrm{D}$ value was $0.93 \times 10^{-3} \mathrm{~mm}^{2} / \mathrm{s}$. c $f$-value curve. This reflects the perfusion fraction, the corresponding f-value was $28.08 \%$. d D* value curve. This reflects intravascular perfusion, the corresponding $\mathrm{D}^{*}$ value was $92.17 \times 10^{-3} \mathrm{~mm}^{2} / \mathrm{s}$

\section{Results}

\section{IVIM-DWI}

Six of the pregnant women were excluded because of fetal movement artifacts which caused obvious signal attenuation. A total of 67 pregnant women (56 women in the normal groups and 11 women in the late-onset FGR group) were included in the analysis.

Multiple-b-value DWI signal analysis was carried out. The PRIDE DWI Tool software (Version 1.5, Philips Healthcare) was used to automatically generate perfusion correlation parameter diagrams ( $f$ and $D^{*}$ ) and a simple diffusion parameter diagram

- Table 1 ICC calculation results.

\begin{tabular}{|c|c|c|c|c|c|c|c|}
\hline \multirow[t]{2}{*}{ Index } & \multirow{2}{*}{$\begin{array}{l}\text { Intraclass correlation } \\
\text { coefficient }^{\mathrm{a}}\end{array}$} & \multicolumn{2}{|l|}{ ICC95\% CI } & \multicolumn{2}{|c|}{ ICC test } & \multicolumn{2}{|l|}{ t-test } \\
\hline & & lower limit & upper limit & $\mathbf{F}$ & p & $T$ & $\mathbf{P}$ \\
\hline$f$ & 0.808 & 0.546 & 0.913 & 5.061 & 0.000 & -0.124 & 0.902 \\
\hline D & 0.881 & 0.732 & 0.947 & 9.301 & 0.000 & -2.045 & 0.051 \\
\hline $\mathrm{D}^{*}$ & 0.754 & 0.458 & 0.888 & 3.983 & 0.000 & 0.567 & 0.575 \\
\hline
\end{tabular}




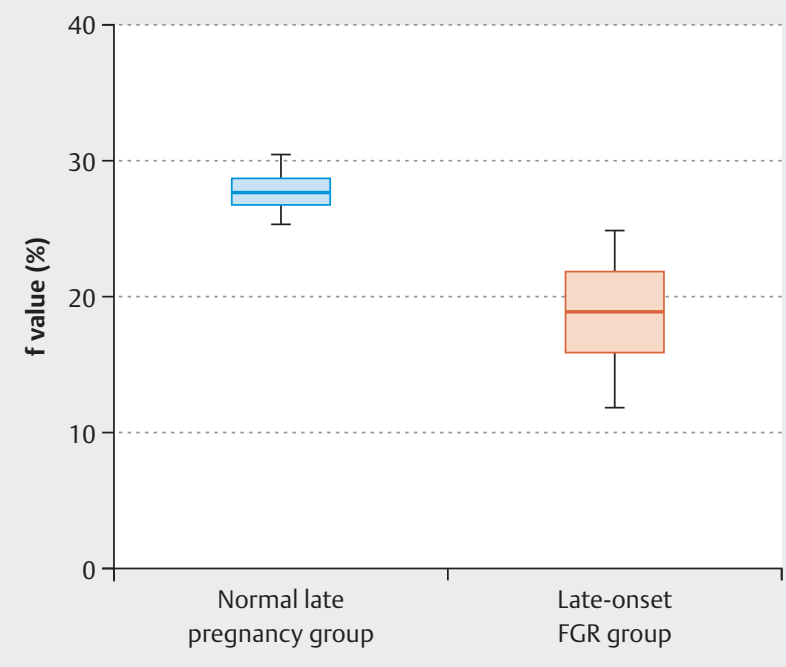

- Fig. 2 Placental perfusion: $f$ values of the normal late pregnancy group and the late-onset FGR group.

(D value). The SAR values of IVIM-DWI sequences were not more than 2.5. As shown in $\boldsymbol{\nabla}$ Fig. $\mathbf{1}$ a, the DWI signal attenuated as the b-value increased. - Fig. $\mathbf{1}$ b shows a simple diffusion model diagram ( $D$ value) which reflects the diffusion of pure water molecules, the corresponding D value was $0.93 \times 10^{-3} \mathrm{~mm}^{2} / \mathrm{s}$. > Fig. $1 \mathrm{c}$ shows the perfusion correlation parameter diagram (f-value) for the tissue perfusion fraction, the corresponding f-value was $28.08 \%$. Fig. 1 d shows the perfusion correlation parameter diagram ( $D^{*}$ value) which reflects capillary perfusion, the corresponding $\mathrm{D}^{*}$ value was $92.17 \times 10^{-3} \mathrm{~mm}^{2} / \mathrm{s}$.
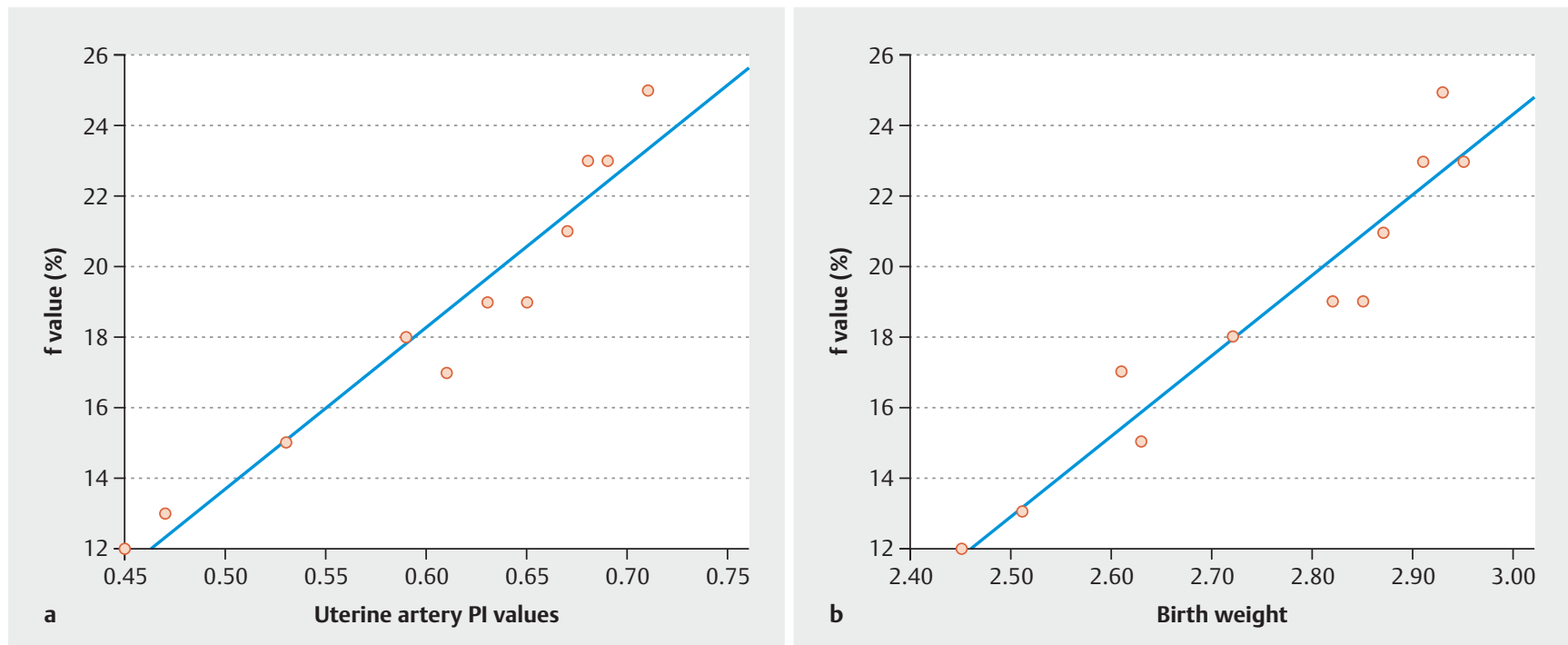

- Fig. 3 Placental perfusion: $\mathrm{f}$ values, uterine artery pulsatility index (PI) values and birth weight. a Uterine artery PI values. b Birth weight.

\section{ICC analysis results}

The results showed that measurement repeatability for $f$ and $D$ values was good ( $\triangleright$ Table 1 ). Repeatability was best for $D$ values $(\mathrm{ICC}=0.881, \mathrm{~F}=9.301, \mathrm{p}<0.05)$; the repeatability of $\mathrm{f}$-values was second best $(I C C=0.808, F=5.061, p<0.05)$. The repeatability of $D^{*}$ values was average $(I C C=0.754, F=3.983, p<0.05)$.

\section{Perfusion fraction for the normal late pregnancy group and the late-onset FGR group}

As shown in > Fig. 2, the f-values of the late-onset FGR group were significantly lower than those of the normal late pregnancy group (19.07 vs. $27.78 \%$ ). Moreover, uterine artery pulsatility in$\operatorname{dex}(\mathrm{PI})$ values of the late-onset FGR group were markedly increased compared to those of the normal late pregnancy group (1.96 vs. 1.03, - Fig. 3 a), while the birth weights for the late-onset FGR group were significantly lower $(2.75$ vs. $3.18 \mathrm{~kg}$, - Fig. 3b). There was a significant positive correlation between $\mathrm{f}$ values and uterine artery PI values and birth weight $(r=0.968$, $p<0.01 ; r=0.959, p<0.01 ;>$ Fig. 3 ). There was a significant negative correlation between $\mathrm{f}$-values and $\mathrm{GA}(r=-0.534, \mathrm{p}<0.01)$, but $D$ and $D^{*}$ values were not correlated with $G A(r=-0.268$, $p=0.177 ; r=-0.222, p=0.266)$.

\section{Discussion}

\section{Clinical and pathological manifestations of FGR}

FGR is associated with a higher rate of stillbirths and higher rates of perinatal and early neonatal mortality. Early-onset FGR is associated with fetal gene or chromosome abnormalities [8]. Late-onset FGR is highly associated with severe placental insufficiency and unequal fetal development (fetal body length and diameter are appropriate for GA, but the body weight is low) due to complications such as pregnancy-induced hypertension [9]. Timely prenatal and b 
intrapartum treatment can improve the prognosis of FGR, but the successful treatment of FGR during pregnancy depends on early diagnosis. Placental villous infarction, vasculo-syncytial membrane thickening, intervillous thrombus, chorioamnionitis and increased vasculitis activity have all been reported to be associated with FGR [10]. Deficient maternal circulation in the villi results in ischemic infarction of the villi, and more than $10 \%$ of villi infarctions are associated with fetal hypoxia. The current study found that the perfusion fraction was significantly lower in the late-onset FGR group compared to the normal late pregnancy group, which was in accordance with the hemodynamic changes caused by the pathological changes of FGR. The perfusion fraction was also found to be significantly related to birth weight and to uterine artery PI values. This indicates that the perfusion fraction ( $f$-value) may have a certain predictive value for FGR and could become an evaluation tool for when planning a clinical delivery for FGR in future.

\section{Principle of IVIM and parameter settings}

The IVIM method was first proposed by Le Bihan and colleagues in 1986 [3]. They differentiated tissues into two different proton pools, namely, a water molecule diffusion proton pool inside and outside the cell and a blood flow proton pool in the capillaries. Perfusion and diffusion data can be obtained at the same time using a bi-exponential model. Because contrast media may pass the placental barrier during pregnancy, placental perfusion data should preferably be obtained by non-contrast-enhanced methods. The three parameters $\left(D, D^{*}, f\right)$ can be estimated from the data of DWI images acquired using multiple b-values. D is referred to as the slow diffusion coefficient and represents the diffusion of pure water molecules. $D^{*}$ is referred to as the fast diffusion coefficient; it depicts capillary perfusion, and is affected by the velocity of blood flow and capillary morphology. $f$ is referred to as the perfusion score and represents the proportion of fast diffusion components associated with microcirculation instillation in the total diffusion; it is usually related to the volume of blood. In terms of sequence parameter settings, IVIM-DWI needs to include multiple high and low b-value images to calculate the relevant parameters. At present, the low b-value for IVIM-DWI in the abdomen is generally set to less than $200 \mathrm{~mm}^{2} / \mathrm{s}$ [11], and more than 4 b-values are needed to calculate the multiple parameters of IVIM. To ensure the accuracy of the perfusion-related parameters ( $f, D^{*}$ ), this study used 11 b-values $(0,10,30,50,70,100,150,200$, $\left.500,800,1000 \mathrm{~s} / \mathrm{mm}^{2}\right), 8$ of which were low b-values, to calculate the perfusion parameters.

Compared with conventional color Doppler imaging of the uterine artery, IVIM offers the following advantages:

1. Volume scanning can measure the perfusion volume of the entire placenta by appropriate drawing of the ROI; moreover, there is no need to locate the feeding vessels.

2. IVIM is not affected by the amount of amniotic fluid, by maternal obesity or by placental position, and does not depend on the operator's experience.

3. IVIM is more commonly used to measure the intravascular movement of the placenta than placental blood flow because the latter is more consistent with real placenta perfusion characteristics, and it is also because of this movement to ensure adequate maternal blood filling.

\section{Feasibility analysis of IVIM for placental examination}

Because the placenta is large, has a relatively fixed position and is abundantly perfused (about $50 \%$ of placental volume is placental blood), the high level of placental perfusion makes it easy to carry out quantitative measurements using MRI perfusion-sensitive imaging. IVIM needs more b-values, but the acquisition time is usually longer. In order to reduce the influence of maternal respiratory artifacts, a respiratory triggering method was used in this study. The placental IVIM scan was done in the morning to reduce artifacts from maternal intestines and fetal movement. We also first performed a structural scan to allow the fetus adapt to the noise and then carried out the placental IVIM scan. Except for 6 cases where fetal movement artifacts caused obvious attenuation of the image signals, the results from the other 67 cases showed that multiple-b-images could meet diagnostic requirements.

In the UK, the Medical Devices Agency guidelines require SAR values in the fetus to be less than $10 \mathrm{~W} / \mathrm{kg}$ during MRI [12]. In China, Zhu Ming et al. [13] are of the opinion that MRI examinations can be safely carried out at 14-40 weeks of pregnancy. Therefore, based on suggestions from previous studies, women who were 24 weeks pregnant were chosen as research subjects in the current study, and SAR values were strictly controlled during scans. In this study, the peak SAR values were never more than 2.5, which indicates that placental IVIM examination is feasible in terms of imaging quality and safety.

\section{Repeatability analysis of placental IVIM data}

The instability of low b-value image signal measurements and the increased difficulty of applying a fitting algorithm results in a relative decrease in the stability of perfusion-related parameters ( $f$, $\left.D^{*}\right)$. Our study compared the consistency of parameter measurements between different observers using the intraclass correlation coefficient. Our results showed that $D^{*}$ parameter images had a poor signal-to-noise ratio. The use of $\mathrm{D}^{*}$ was limited by measurement errors which made it difficult to provide accurate and consistent data on tissue perfusion. $\mathrm{D}^{*}$ is of limited significance for clinical diagnosis and research. The repeatability for the simple diffusion coefficient (D) and for the perfusion fraction (f) were good, and they could be used as stable and credible indexes to evaluate diffusion and perfusion in placental tissue.

\section{Correlation between $\mathrm{f}$-value and GA}

Studies suggest that as GA, placental villi proliferation and villous maturation increase, the number of villi, the villi length and the surface area of the villi also increase [14]. However, as GA increases, the blood flow volume per unit of villi surface area decreases, due to a narrowing of the intervillous space. Our findings were consistent with that (i.e., the perfusion fraction f-value decreased as GA increased). However, the change in D values was not correlated with GA, indicating that placental maturation processes may be mainly reflected in vascularization processes and may not be related to physical characteristics such as cell size and membrane permeability. In addition, there was no statistical correlation between $\mathrm{D}^{*}$ values and GA, possibly because $\mathrm{D}^{*}$ values are more sensitive to blood flow velocity [15] 


\section{Conclusion}

In summary, our results showed that IVIM technology can accurately quantify placental perfusion. In our study, f-values were found to be strongly correlated with uterine artery blood flow resistance as measured by color Doppler and may have a certain predictive value for late-onset FGR. However, we need to expand the sample size to further evaluate the value of perfusion parameters for predicting FGR and to relate imaging findings to postnatal histological findings. IVIM could provide new options for evaluating placental microcirculation in pregnant women when the use of contrast agents is severely limited.

\section{Conflict of Interest}

The authors declare that they have no conflict of interest.

\section{References}

[1] Figueras F, Caradeux J, Crispi F et al. Diagnosis and surveillance of lateonset fetal growth restriction. Am J Obstet Gynecol 2018; 218: S790S802.e1

[2] Monaghan C, Thilaganathan B. Fetal Growth Restriction (FGR): How the Differences Between Early and Late FGR Impact on Clinical Management? Journal of Fetal Medicine 2016; 3: 1-7. doi:10.1007/s40556016-0098-7

[3] Le Bihan D, Breton E, Lallemand D et al. MR imaging of intravoxel incoherent motions: application to diffusion and perfusion in neurologic disorders. Radiology 1986; 161: 401-407

[4] Sara S, Peter L, Ajlana L et al. OP003. Placental perfusion in normal pregnancy and in early and late preeclampsia: A magnetic resonance imaging study. Pregnancy Hypertens 2013; 3: 63
[5] Moore RJ, Strachan BK, Tyler D] et al. In utero perfusing fraction maps in normal and growth restricted pregnancy measured using IVIM echo-planar MRI. Placenta 2000; 21: 726-732

[6] Ong SS, Tyler DJ, Moore RJ et al. Functional magnetic resonance imaging (magnetization transfer) and stereological analysis of human placentae in normal pregnancy and in pre-eclampsia and intrauterine growth restriction. Placenta 2004; 25: 408-412

[7] Moore RJ, Issa B, Tokarczuk P et al. In vivo intravoxel incoherent motion measurements in the human placenta using echo-planar imaging at 0.5 T. Magn Reson Med 2000; 43: 295-302

[8] Riyami NA, Walker MG, Proctor LK et al. Utility of head/abdomen circumference ratio in the evaluation of severe early-onset intrauterine growth restriction. J Obstet Gynaecol Can 2011; 33: 715-719

[9] Mifsud W, Sebire NJ. Placental Pathology in Early-Onset and Late-Onset Fetal Growth Restriction. Fetal Diagn Ther 2014; 36: 117-128

[10] Vedmedovska N, Rezeberga D, Teibe U et al. Placental pathology in fetal growth restriction. Eur J Obstet Gynecol Reprod Biol 2011; 155: 36-40

[11] Kim SY, Lee SS, Byun JH et al. Malignant hepatic tumors: short-term reproducibility of apparent diffusion coefficients with breath-hold and respiratory-triggered diffusion-weighted MR imaging. Radiology 2010; 255: 815-823

[12] Bulas D, Egloff A. Benefits and risks of MRI in pregnancy. Semin Perinatol 2013; 37: 301-304

[13] Dong SZ, Zhu M. Utility of fetal cardiac magnetic resonance imaging to assess fetuses with right aortic arch and right ductus arteriosus. J Matern Fetal Neonatal Med 2018; 31: 1627-1631

[14] Salomon C, Torres MJ, Illanes S et al. Placental cell-derived exosomes increase in maternal circulation with gestational age. Placenta 2013; 34: A79-A80

[15] Andreou A, Koh DM, Collins D] et al. Measurement reproducibility of perfusion fraction and pseudodiffusion coefficient derived by intravoxel incoherent motion diffusion-weighted MR imaging in normal liver and metastases. Eur Radiol 2013; 23: 428-434 